length $16 \pm 4 \AA$. longer than the lines which they accompany, are readily accounted for as due to the heavier of the two isotopes, atomic weights 35 and 37 , of which Aston (Phil. Mag., vol. xxxix., p. 611, 1920) has shown ordinary chlorine to consist. An approximate theory shows the wave-length of the band centre to vary as the square root of the effective mass, $m=\frac{m_{1} m_{2}}{m_{1}+m_{2}}$, where $m_{1}$ is the mass of the hydrogen nucleus and $m_{2}$ that of the chlorine atom. Taking $m=35 / 36$ for the lighter and $37 / 38$ for the heavier isotope, the calculated difference between the wavelengths of corresponding lines for the two isotopes comes out $I_{3} \AA$. This is much larger than the differences of about $0.004 \AA$. which have been found between lines of the isotopes of lead (Aronberg, Astrophysical Journal, vol. xlvii., p. 96, I918, and Merton, Roy. Soc. Proc., A, vol. xcvi., p. 388 , 1920).

I hope soon to publish a more detailed account of the theory and measurements of these lines, probably in the Astrophysical Journal. F. W. Loomis.

New York University, University Heights, New York City, U.S.A.

\section{A New Visual Illusion.}

A VISUal illusion which I have never seen referred to may be of interest. If the gaze is steadily fixed for a few minutes on a spot in the descent of a waterfall which has a fairly long unbroken fall, and afterwards quickly transferred to the adjacent hillside, the hill itself appears to rise slowly as a whole, somewhat as though it were an elevator. The same result mav be obtained by looking fixedly at the broken surface of a rapid and fairly wide stream; on directing the eyes suddenly to the opposite bank this appears to move slowly up-stream.

The illusion seems to me to be due to the rapidly moving water tending to carry the vision along in its own direction, as occurs when any moving object is unreflectively observed. But while the eyes are kept fixed on the selected point, this tendency becomes counteracted by a series of slight and rapid but unconscious muscular efforts which prevent the eyes from following the motion. After the gaze is removed to the adjacent stationary ground, these muscular efforts automatically persist for a short time, thus causing the ground to appear to move in the opposite direction to that of the water. But possibly a more accurate explanation can be advanced.

J. E. TURNER.

55 Allerton Road, Mossley Hill, Liverpool.

\section{Plant-life in the Cheddar Caves.}

Since reading the letter relating to plant-growths in the Cheddar caves by Mr. L. Pendred which appeared in Narure of August 5, I have been able, by the courtesy of Messrs. Gough, to examine the plants in situ, and to secure a quantity of material for fuller investigation.

The green patches on the cave-walls were found to consist of a small green unicellular alga. The loose cave-earth on the sides of the cave-paths yielded a few specimens of fern prothallia. The plant patches in the neighbourhood of the electric lights were found to consist of the following species of mosses: Plagiothecium denticulatum, Amblystegium serpens, and Fissidends bryoides, all of which are fairly common. My determinations of these species have been confirmed by Mr. A. Gepp, of the botanical department of the British Museum (Natural History).

I think Mr. Pendred's suggestion that the spores NO. 2658 , VOL. IO6] were carried into the caves by the spades or on the clothes of the workmen is highly probable, or that the excellent ventilation maintained in the caves may have resulted in the spores being carried in by air-currents. In any event, the dampness and the air-currents would be factors assisting in the subsequent germination of the spores.

Armstrong College, Newcastle-upon-Tyne.

\section{Old Maps.}

REFERRING to the kind notice of my presidential address to the Conference of Delegates at the Cardiff meeting of the British Association in NaTURE of September 16 , p. 90, time did not permit details to be given of the evolution of Scottish maps, or those of Faden, etc., would certainly have been referred to. The large map of Cary's which I mentioned was not the one you surmise, "with the coach roads coloured in blue, which is on the scale of five miles to an inch," but the map on the scale of tro miles to an inch. The typist or printer, quite pardonably, has apparently mistaken my "two" for "ten." With regard to Griffith's map of Ireland, I still contend that the date of the map "to be included as a classic" is that of 1853 . I know there was a slightly improved edition in 1855; there is one in the library of the Geological Society of London, but that was the third edition, and not the second, as stated in your columns.

The Museum, Hull.

I confess that I was not aware of a large map by J. Cary on the scale of one inch to two miles. The one that I mentioned, with mail-coach routes in blue, is of constant service to me. Great confusion has been caused in regard to Griffith's geological maps of Ireland by references to them as successive editions, as if all were published and on the same plan and scale. Maxwell H. Close (Journ. R. Greol. Soc. Ireland, vol. v., p. 136, I879) is, I think, responsible for calling a geological map exhibited in ${ }^{18} \mathrm{I}_{5}$ " the first edition," but he carefully added that it was never printed, and he evidently meant only "the first form." He emphasised the fact, by underlining the word, that W. Smith's map of England was published in the same year. Griffith's map of 1835 was, according to John Phillips (op. cit. above, p. $\left.{ }_{13} 8\right)$, large, but also unpublished. Phillips utilised its details in 1838 . In 1838 a coloured geological map by Griffith was issued in connection with the Report of the Railway Commissioners, scale one inch to ten miles. A few montins later in the same year his large map (one inch to four miles) appeared under the same auspices, and was, as Close tells us, sold to the public from March 28, I 839 . These two maps of $188_{3} 8$ can scarcely be called two editions of the same ground. work, since they were both simultaneously in pre. paration. The large map of $x \delta_{3} 8$ (published, with date, in 1839 ) was completely revised and reengraved, with the addition of mineral localities, and issued in six sheets in April, 1855, the date being engraved on it against Griffith's signature. The map of 1853 was a small one (one inch to sixteen miles), and was issued in a guide to land-valuers.

The plates of the "classic" map of $x 85.5$ are preserved in the Ordnance Survey Office, Dublin. From inquiries that I have recently made of this office and of the original publishers, no coloured copies seem now to be available.

It is rarely that one has a chance of correcting $\mathrm{Mr}$. Sheppard. 